\title{
Identification of a signalling molecule involved in bacterial intergeneric communication

\author{
Correspondence \\ hxie@mmc.edu
} \\ Hua Xie \\ Received 12 April 2007 \\ Revised 15 June 2007 \\ Accepted 25 June 2007

\author{
Hua Xie, ${ }^{1}$ Xinghua Lin, ${ }^{1}$ Bing-Yan Wang, ${ }^{2}$ Jie Wu ${ }^{1}$ \\ and Richard J. Lamont ${ }^{3}$ \\ ${ }^{1}$ School of Dentistry, Meharry Medical College, Nashville, TN 37208, USA \\ ${ }^{2}$ Department of Periodontics and Endodontics, State University of New York at Buffalo, Buffalo, \\ NY 14214, USA \\ ${ }^{3}$ Department of Oral Biology, University of Florida, Gainesville, FL 32610-0424, USA
}

\section{INTRODUCTION}

Human dental plaque is a multispecies microbial biofilm that is associated with two common oral diseases, dental caries and periodontal disease. More than 700 bacterial species have been detected in the oral cavity, over $50 \%$ of which are identified by culture-independent molecular techniques (Aas et al., 2005). Formation of dental plaque is a highly organized developmental process involving a specific sequence of colonization that results in spatially and temporally organized structures (Kolenbrander et al., 2006). Formation of dental plaque is initiated by Grampositive species, including streptococci and Actinomyces spp., which recognize salivary receptors exposed on the tooth surfaces (Gibbons et al., 1991; Li et al., 2000; Scannapieco et al., 1995). These early colonizers in turn provide new surfaces that attract and recruit succeeding organisms including Gram-negative potential pathogens, such as Porphyromonas gingivalis and Aggregatibacter (Actinobacillus) actinomycetemcomitans (Kolenbrander et al., 2002). Therefore, the early colonizers play a key role in the development of the dental plaque biofilm.

It is recognized that cell-cell communication occurs between bacterial strains, species and genera. A universal language for interspecies bacterial communication is autoinducer-2 (AI-2). LuxS, the AI-2 synthase, has been

The GenBank/EMBL/DDBJ accession number for the $\operatorname{arc} A$ gene sequence of $S$. cristatus is EF435044. discovered in many oral bacteria, including Streptococcus mutans, S. oralis, S. gordonii, P. gingivalis and A. actinomycetemcomitans (Chung et al., 2001; James et al., 2006; Merritt et al., 2005; Rickard et al., 2006). LuxS-dependent intercellular communication appears to play an important role in biofilm formation in the oral cavity. McNab et al. (2003) found that a S. gordonii luxS mutant was unable to form normal biofilms with a LuxS-deficient strain of $P$. gingivalis, and complementation of the luxS mutation in $S$. gordonii restored normal biofilm formation with the luxSdeficient $P$. gingivalis. In addition to communication mediated through soluble extracellular signalling molecules, interspecies crosstalk can occur through direct cellto-cell contact (Aoki et al., 2005). We reported earlier that expression of the $P$. gingivalis fimA gene, encoding the long fimbrial major subunit protein, is repressed by surface extracts of Streptococcus cristatus (Xie et al., 2000). As the long fimbriae of $P$. gingivalis are required to initiate heterotypic biofilm formation with oral streptococci, substrata of S. cristatus do not support the development of a mixed biofilm with $P$. gingivalis (Xie et al., 2000). We show here that arginine deiminase (ArcA) is the inhibitory molecule of $S$. cristatus. The ability of $S$. cristatus to communicate with $P$. gingivalis is diminished in an $\operatorname{arcA}$ mutant. We also provide evidence that the ability of ArcA to repress expression of the fimA in $P$. gingivalis is not correlated with its enzymic activity. This work presents a novel inter-species contact-dependent communication system between $P$. gingivalis and S. cristatus. 


\section{METHODS}

Bacterial strains and growth conditions. The bacterial strains and plasmids are listed in Table 1. Streptococcus strains were grown in Trypticase peptone broth (TPB) supplemented with $0.5 \%$ glucose at $37{ }^{\circ} \mathrm{C}$ under aerobic conditions. S. cristatus CC5A was used as the parental strain for mutant construction. P. gingivalis ATCC 33277 was grown from frozen stocks in Trypticase soy broth (TSB) or on TSB blood agar plates, supplemented with $1 \mathrm{mg}$ yeast extract $\mathrm{ml}^{-1}, 5 \mu \mathrm{g}$ haemin $\mathrm{ml}^{-1}$ and $1 \mu \mathrm{g}$ menadione $\mathrm{ml}^{-1}$, at $37^{\circ} \mathrm{C}$ in an anaerobic chamber $\left(85 \% \mathrm{~N}_{2}, 10 \% \mathrm{H}_{2}, 5 \% \mathrm{CO}_{2}\right)$. Escherichia coli DH5 $\alpha$ was used as the host for plasmids. E. coli strains were grown in L broth at $37^{\circ} \mathrm{C}$. Antibiotics were used when appropriate, at the following concentrations: $100 \mu \mathrm{g}$ gentamicin $\mathrm{ml}^{-1}$ for $P$. gingivalis, $200 \mu \mathrm{g}$ erythromycin $\mathrm{ml}^{-1}$ for E. coli and $10 \mu \mathrm{g}$ erythromycin $\mathrm{ml}^{-1}$ for $S$. cristatus, $2 \mu \mathrm{g}$ tetracycline $\mathrm{ml}^{-1}$ for E. coli and S. cristatus, $50 \mu \mathrm{g}$ ampicillin $\mathrm{ml}^{-1}$ and $50 \mu \mathrm{g}$ kanamycin $\mathrm{ml}^{-1}$ for E. coli.

Partial purification of the S. cristatus inhibitory protein. Surface extracts of $S$. cristatus CC5A were collected by sonication and centrifugation (13000 $\mathrm{g}$ for $30 \mathrm{~min})$ followed by filtration $(0.2 \mu \mathrm{m}$ pore size). The crude extract of CC5A was partially purified by ammonium sulfate fractionation as described earlier (Xie et al., 2004). The fractions precipitated with 33, 42, 50, 55, 60 and $66 \%$ saturated ammonium sulfate were designated AS1, AS2, AS3, AS4, AS5 and AS6, respectively. For further purification, the AS6 fraction $(1 \mathrm{ml})$ was dialysed overnight against Tris buffer $(50 \mathrm{mM}, \mathrm{pH} 7.3)$. The dialysed sample was then applied to a Blue Sepharose column (GE Healthcare), which was pre-washed with the same Tris buffer (Nelson et al., 2001). The non-bound proteins were collected from the column. Bound proteins were eluted with Tris buffer supplemented with $1 \mathrm{mM} \mathrm{NAD}^{+}$.

Proteomic analysis. Samples were separated by SDS-PAGE (12\% gel) along with prestained size standards (Bio-Rad). Coomassiestained protein bands of interest were excised and reduced with $10 \mu \mathrm{l}$
$45 \mathrm{mM}$ dithiothreitol for $20 \mathrm{~min}$ at $37^{\circ} \mathrm{C}$. The gel pieces were then digested with trypsin overnight. The peptides were extracted and reconstituted in $20 \mu \mathrm{l} 0.1 \%$ trifluoroacetic acid. Approximately $0.4 \mu \mathrm{l}$ of the peptides were spotted onto a MALDI plate. For each individual sample, the MALDI-TOF mass spectrum and the corresponding MS/ MS fragmentation spectra were collectively searched against the SWISS-PROT database using GPS Explorer software (Applied Biosystems) running the MASCOT database search engine (MatrixScience). MALDI-TOF peptide mass maps were internally calibrated to within 20 p.p.m. mass accuracy using trypsin autolytic peptides $(\mathrm{m} / \mathrm{z} 842.51$ and 2211.10$)$.

Sequencing of the $\boldsymbol{S}$. cristatus arcA gene. The entire $\operatorname{arcA}$ gene of $S$. cristatus CC5A was amplified by the primers 5'-GTACCGATGGTCTTGTTTGA-3' and 5'-AGGTATTCTAACTCTGCACG$3^{\prime}$, which were designed based on the completely conserved regions among Streptococus suis flps (AF546864), Streptococcus equi subsp. zooepidemicus arcA (AB210842) and the Streptococcus gordonii DL1 arc operon (AF534569). The PCR product was cloned into pCRIITOPO vector (Invitrogen) and sequenced by using an ABI capillary sequencer (Perkin-Elmer). The sequence is deposited in GenBank (accession number EF435044).

Construction of the $S$. cristatus $\operatorname{arcA}$ mutant and $\operatorname{arcA-}$ complemented strains. An insertional $\operatorname{arcA}$ mutant was generated by using ligation-independent cloning of PCR-mediated mutagenesis (LIC-PCR) (Aslanidis \& de Jong, 1990). This procedure involved three steps of PCR to introduce a $2.1 \mathrm{~kb}$ ermF-ermAM cassette (Fletcher et al., 1995) into the $\operatorname{arcA}$ gene. First, the upstream DNA fragment ( $549 \mathrm{bp}$ ) of the $\operatorname{arcA}$ gene was amplified by using Taq RNA polymerase (1 U, Invitrogen) and chromosomal DNA of $S$. cristatus CC5A $(0.1 \mu \mathrm{g})$ as template with specific primers (5' -ATGTCTACACATCCAATTC- $3^{\prime}$ and $5^{\prime}$-GATGTTGCAAATACCGATGAGCATCTGCATACATGTGGTTGA- $3^{\prime}$ ) containing the sequence (underlined)

Table 1. Strains and plasmids used in this study

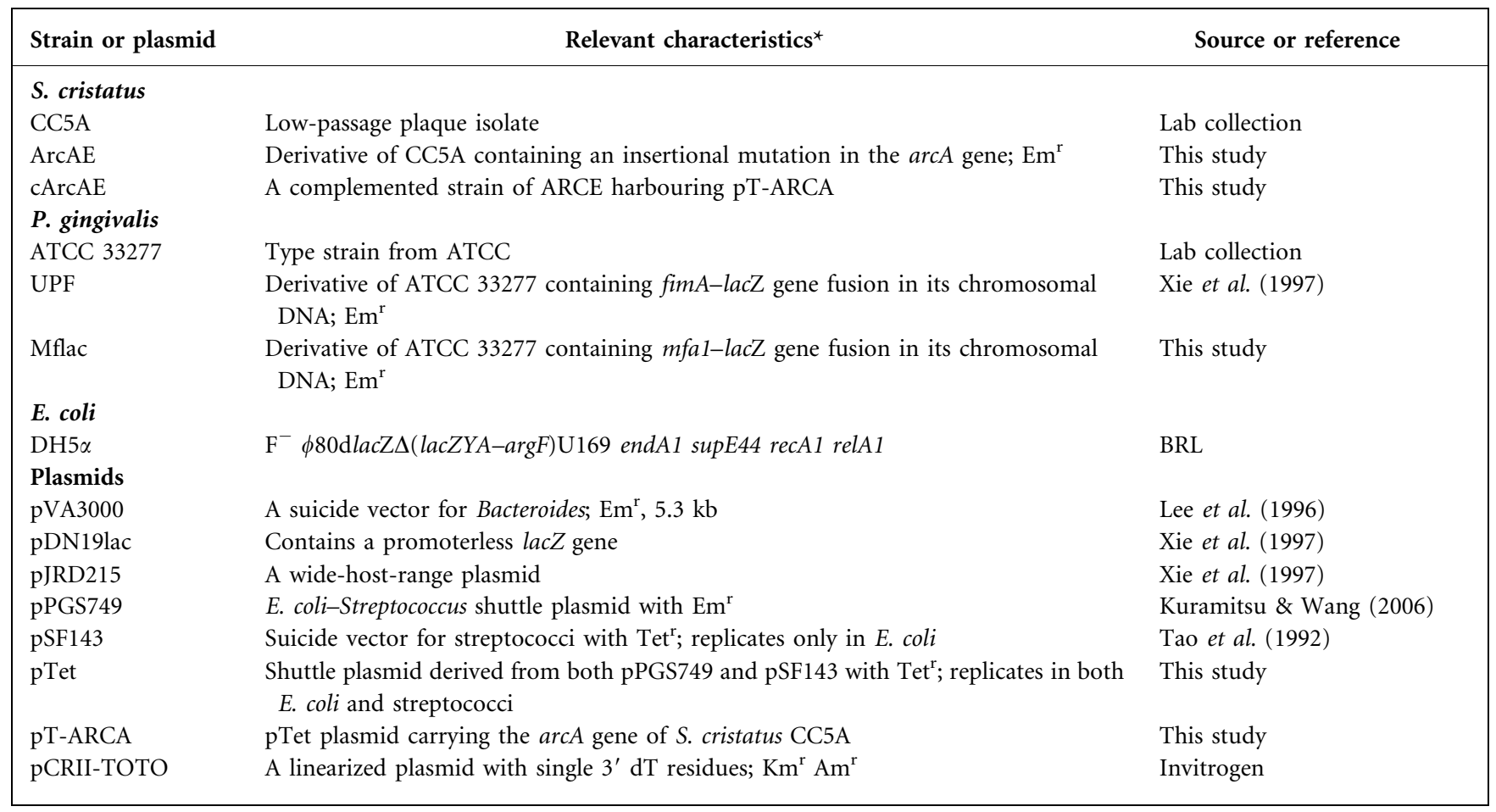

${ }^{\star} \mathrm{Km}^{\mathrm{r}}, \mathrm{Tet}^{\mathrm{r}}, \mathrm{Em}^{\mathrm{r}}, \mathrm{Am}^{\mathrm{r}}$, resistance to kanamycin, tetracyline, erythromycin and ampicillin, respectively. 
corresponding to the $5^{\prime}$ end of the ermF-ermAM cassette. The downstream DNA fragment (549 bp) of the $\operatorname{arcA}$ gene was amplified with specific primers (5'-ACAACGAGGTCCACCACG-3' and $5^{\prime}$ CCTCTAGAGTCGACCTGCAGATCGAAGGTGGAGATGAGTT-3') containing the sequence (underlined) corresponding to the $3^{\prime}$ end of the ermF-ermAM cassette. Primers 5'-GCTCATCGGTATTTGCA-

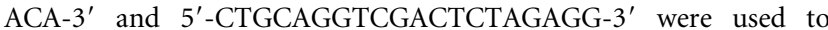
amplify the ermF-ermAM cassette. Each PCR product of the $\operatorname{arcA}$ gene was then ligated with the ermF-ermAM cassette by the second PCR step with primers arcAF and ermR or primers ermF and arcAR, respectively. The second-step PCR products (100 ng) were then mixed and used as template with arcAF and arcAR as primers in the third PCR step to create the fragment $\operatorname{arcA}$-erm-arcA containing the ermF-ermAM cassette flanked with upstream and downstream fragments of $\operatorname{arcA}$.

The arcA-erm-arcA fragment was introduced into S. cristatus CC5A cells by DNA transformation (Wang \& Kuramitsu, 2005). arcAdeficient mutants were constructed via a double-crossover event that introduces the arcA-erm-arcA fragment into the CC5A chromosome. The mutants were selected on TPB plates supplemented with erythromycin $\left(10 \mu \mathrm{g} \mathrm{ml}^{-1}\right)$. The mutations were confirmed by PCR analysis, and the one selected for study was designated S. cristatus ArcAE.

An E. coli-Streptococcus shuttle vector was used to construct a complemented strain of ArcAE. To create the E. coli-Streptococcus shuttle vector, plasmid pSF143 (obtained from L. Tao, University of Illinois, Chicago, IL, USA), which replicates only in E. coli, was digested with HincII and BamHI to obtain a $5.4 \mathrm{~kb}$ fragment containing a tetracycline-resistance gene (Tobian et al., 1984). Plasmid pPGS749 (Kuramitsu \& Wang, 2006) was digested with SmaI and BglII, and a $2.2 \mathrm{~kb}$ fragment that contains a Rep origin which replicates in streptococci was purified using a QIAEX II Gel Extraction kit (Qiagen). The two fragments were ligated using T4 ligase to generate pTet, a shuttle plasmid with tetracycline resistance that replicates in both $E$. coli and streptococci. pTet was then used for complementation of the $\operatorname{arcA}$ gene. The encoding region of CC5A $\operatorname{arcA}$ along with $330 \mathrm{bp}$ of upstream sequence from the potential start codon was amplified by PCR with primers $5^{\prime}$-GCGGTACCTCAGCTATGAGCACAAACAG (KpnI site underlined), and $5^{\prime}$ GCCCATGGACAACGAGGTCCACCACG ( $\mathrm{NcoI}$ site underlined). The PCR product was cloned into pTet vector. The recombinant plasmid, pT-ARCA, was introduced by transformation into the $\operatorname{arcA}$ deficient mutant, S. cristatus ArcAE, to create $S$. cristatus cArcAE. After transformation, erythromycin- and tetracycline-resistant transconjugants were selected, and plasmid identity was confirmed by PCR analysis.

Cloning and expression of the $\operatorname{arcA}$ gene in $\boldsymbol{E}$. coli. $\operatorname{arc} A$, encoding arginine deiminase, was amplified by PCR with primers $5^{\prime}$ GCGGTACCTATGTCTACACATCCAATTC-3' (KpnI site underlined) and 5'-GCGAGCTCACAACGAGGTCCACCACG-3' (SacI site underlined), which produced a $1200 \mathrm{bp}$ PCR product. The PCR product was then cloned into pCRII-TOPO (Invitrogen). Recombinant arginine deiminase (rArcA) was expressed in E. coli by using a pThiohis protein expression system (Invitrogen). The $\operatorname{arcA}$ DNA fragment was subcloned into pThiohis-A downstream of a His tag. The recombinant ArcA was expressed in E. coli $\mathrm{DH} 5 \alpha$ cells carrying the pThiohis-A/arcA plasmid in the presence of IPTG and kanamycin. His-tagged rArcA was purified with ProBond resin (Invitrogen). The His-tag on the recombinant protein was cleaved with enterokinase and removed by His-bind resin. Enterokinase was then removed by using Ekapture agarose.

Arginine deiminase assay. The arginine deiminase assay was performed in 96-well microplates as described by Thirkill et al. (1983). S. cristatus CC5A protein samples were adjusted with PBS to a constant $100 \mu \mathrm{l}$ volume in each well, and mixed with $50 \mu 10.1 \mathrm{M} \mathrm{L-}$ arginine. The mixtures were allowed to react for $1 \mathrm{~h}$ at $37{ }^{\circ} \mathrm{C}$ and the reactions were then terminated by the addition of $50 \mu \mathrm{l} 20 \%$ sulfuric acid. Finally, $1 \%$ 2,3-butanedione monoxime (Sigma) was added to each well, and the reaction was developed by incubation in the dark for $1 \mathrm{~h}$ at $56{ }^{\circ} \mathrm{C}$. The peach colour was quantified with a Benchmark plus microplate spectrophotometer (Bio-Rad) at $492 \mathrm{~nm}$.

Construction of $\boldsymbol{P}$. gingivalis Mflac strain. A $P$. gingivalis strain carrying an $m f a 1$ promoter-lac $Z$ fusion was generated by the method described before (Xie et al., 1997). Briefly, the $m f a 1$ promoter region was amplified by PCR with primers $5^{\prime}$-ACCCATCCTCTGTCTTCTGC- $3^{\prime}$ and $5^{\prime}$-CTCGTTATCACATATCCGAACC- $3{ }^{\prime}$, and cloned into pDN19lac to generate the mfal promoter-lacZ fusion. The recombinant plasmid was introduced into P. gingivalis ATCC 33277 by conjugation. The $P$. gingivalis transconjugants (Mflac) were selected on TSB plates containing $10 \mu \mathrm{g}$ erythromycin $\mathrm{ml}^{-1}$.

$\boldsymbol{\beta}$-Galactosidase assays. S. cristatus protein fractions $(25 \mu \mathrm{g})$ were mixed with $10^{5}$ cells of $P$. gingivalis UPF, which contains a chromosomal fimA promoter-lacZ reporter construct, and spotted onto a TSB blood agar plate. The ability of the fractions to inhibit fimA expression in $P$. gingivalis was determined with a $\beta$-galactosidase assay. Expression of the lac $Z$ gene under control of the fimA promoter was measured by the standard spectrophotometric $\beta$-galactosidase assay with ONPG as the substrate, as described by Xie et al. (1997).

\section{RESULTS}

\section{Identification of $\mathbf{S}$. cristatus inhibitory protein}

We reported previously that the expression of the fimA gene is repressed in the presence of surface extracts of $S$. cristatus, but not in the culture medium, indicating the presence of a LuxS-independent intergeneric communication system (Xie et al., 2000). To purify the signal molecule, we first fractionated S. cristatus CC5A surface extracts by ammonium sulfate precipitation (Xie et al., 2004). For further purification, the active fraction (AS6, $1 \mathrm{ml}$ ) was then applied to a Blue Sepharose column to remove glyceraldehyde-3-phosphate dehydrogenase, one of the major proteins in the AS6 fraction. The non-bound proteins were collected from the column and the fractions were analysed by SDS-PAGE. To test their ability to repress fimA expression in $P$. gingivalis, each fraction was mixed with $P$. gingivalis UPF, a strain carrying a fimA promoterlac $Z$ fusion. Expression of the lac $Z$ gene under the control of the fimA promoter was measured by $\beta$-galactosidase assay (Xie et al., 1997). The results shown in Fig. 1 reveal that a protein band of approximately $47 \mathrm{kDa}$ had a high correlation with the inhibitory activity. The ability to repress fimA expression was enhanced as the purity of this $47 \mathrm{kDa}$ protein increased. The expression of fimA in $P$. gingivalis was inhibited by as much as $96 \%$ by the unbound fraction after Blue Sepharose column chromatography (Fig. 1). These data suggested the involvement of the $47 \mathrm{kDa}$ protein in intergeneric communication between $S$. cristatus and $P$. gingivalis.

To identify the $47 \mathrm{kDa}$ protein, we performed in-gel digestion followed by MALDI-TOF mass spectrometry, as 


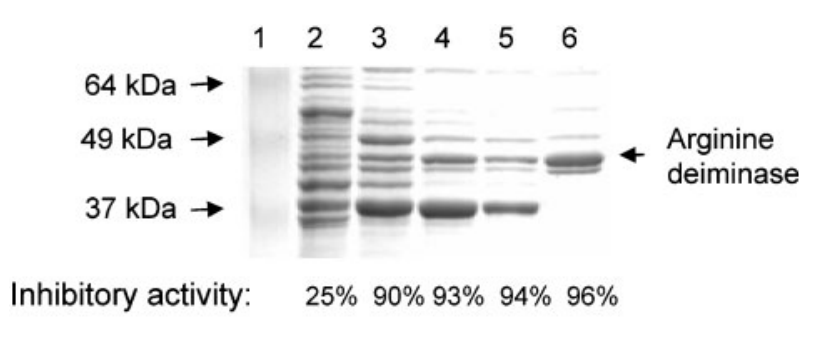

Fig. 1. SDS-PAGE analysis and inhibitory activity of the fractions of $S$. cristatus surface proteins. Surface extracts of $S$. cristatus were precipitated with ammonium sulfate at increasing concentrations, separated by SDS-PAGE and stained with Coomassie blue. Lane 1, molecular size standards; lane 2, ammonium sulfate (AS) fraction AS3; lane 3, AS4; lane 4, AS5; lane 5, AS6; lane 6, Blue Sepharose unbound fraction of AS6. Molecular sizes and the ArcA band are denoted by arrows. Inhibitory activity is expressed as $\%$ reduction (compared to buffer control) of LacZ activity in $P$. gingivalis UPF, a strain carrying the transcriptional fusion of a promoterless lac $Z$ and the $\operatorname{fim} A$ promoter region.

described in Methods. Searches against the SWISS-PROT database identified the protein as arginine deiminase (ArcA). Identification was accepted based on the significant molecular weight search (MOWSE) scores. Protein scores greater than 66 are significant $(P<0.05)$. The score for the $47 \mathrm{kDa}$ protein was 604 . The molecular mass $(46752 \mathrm{Da})$ of streptococcal ArcA is consistent with the corresponding region of the gel as determined by the molecular mass markers.

\section{Activity of the $\operatorname{arcA}$ mutant and complemented strains}

To confirm the role of ArcA in regulation of fimA expression, we constructed an $\operatorname{arcA}$ mutant of $S$. cristatus. Insertional inactivation of the $S$. cristatus $\operatorname{arcA}$ gene resulted in a prolonged lag period under the standard growth conditions for streptococci (Fig. 2). This is not surprising since the arginine deiminase pathway is partly responsible for ATP regeneration in bacteria (Crow \& Thomas, 1982). Comparison of the ammonium sulfate precipitation fractions AS6 between wild-type CC5A and the mutant strain ArcAE showed that a $47 \mathrm{kDa}$ band was missing from the mutant (Fig. 3a). Furthermore, mutation of $\operatorname{arc} A$ abrogated the inhibitory activity toward $P$. gingivalis fimA expression (Fig. 3b), indicating that arginine deiminase is indeed an effector molecule mediating communication between $S$. cristatus and $P$. gingivalis.

The arginine deiminase operon has been extensively studied in S. gordonii DL1 (Caldelari et al., 2000; Dong et al., 2002; Zeng et al., 2006) and consists of five genes that encode enzymes involved in the conversion of arginine to ornithine, ammonia and $\mathrm{CO}_{2}$ with the concomitant production of ATP (Dong et al., 2002). arcA is the first gene in this operon. To eliminate the possibility that a polar effect plays a role in

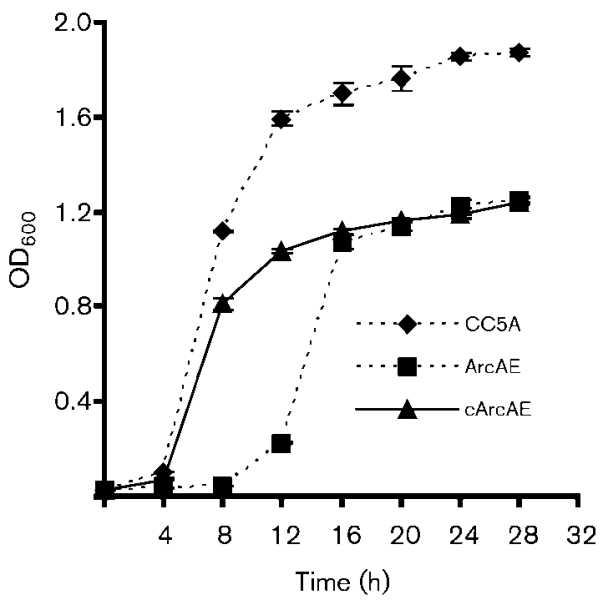

Fig. 2. Comparison of the growth curves of $S$. cristatus strains in TSB medium. The data points are means \pm SEM of four samples (error bars not shown where smaller than symbols). Samples of $1 \mathrm{ml}$ were taken and the $\mathrm{OD}_{600}$ was measured over a period of $30 \mathrm{~h}$.

abolishing inhibitory activity in the $\operatorname{arcA}$ mutant, we complemented the mutant with the wild-type allele in trans. As shown in Fig. 3(a), production of ArcA was restored in the complemented strain cArcAE, although the expression level was lower compared to the parental CC5A strain. Complementation of the $\operatorname{arcA}$ mutant with the $\operatorname{arcA}$ gene partially restored the wild-type phenotype, since surface extracts isolated from the complemented strain cArcAE inhibited $50 \%$ of fimA expression in P. gingivalis (Fig. 3b).

\section{Activity of recombinant ArcA protein}

We further confirmed the role of arginine deiminase in the repression of fimA expression in $P$. gingivalis by cloning and expressing $\operatorname{arcA}$ in E. coli. The fimA expression was repressed 2.5- to 3-fold in the presence of the recombinant protein (rArcA) (Fig. 3b), although the inhibitory activity was not as high as that of the natural protein, which was able to inhibit $96 \%$ of the fimA expression (Fig. 1). This could be due to incorrect folding or post-translational modification in the heterologous host. The role of rArcA in expression of the short fimbriae ( $m f a 1)$ was also examined by using a $P$. gingivalis strain carrying an $m f a 1-l a c Z$ fusion. In the presence of rArcA, the promoter activity of $m f a 1$ was not modulated in $P$. gingivalis (Fig. $3 \mathrm{~b}$ ), suggesting a specific role of $S$. cristatus ArcA in fimA expression. As a control, a major surface protein, glyceraldehyde-3-phosphate dehydrogenase (GAPDH), of S. cristatus CC5A was also cloned and expressed in E. coli. The rGAPDH had no effect on fimA expression (data not shown).

\section{Dual function of arginine deiminase}

While the arginine deiminase system is found in many bacteria (Burne \& Marquis, 2000), relatively few arginine 

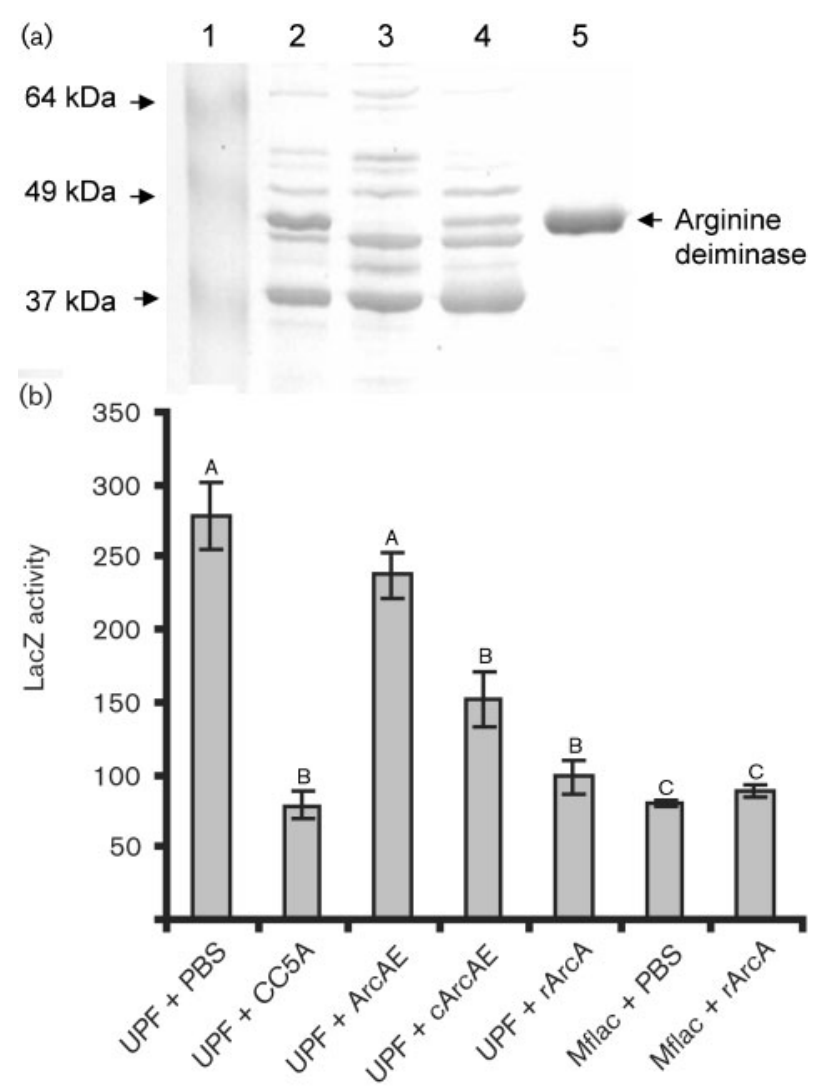

Fig. 3. Inhibition of fimA expression in P. gingivalis by ArcA. (a) $S$. cristatus surface proteins were subjected to SDS-PAGE (12\%) and stained with Coomassie blue. Lane 1, molecular mass markers; lane 2, ammonium sulfate fraction AS6 of CC5A; lane 3 , ammonium sulfate fraction AS6 of $\operatorname{ArcAE}$ ( $\operatorname{arc} A$ mutant); lane 4, ammonium sulfate fraction AS6 of cArcAE ( $\operatorname{arc} A$ mutant complemented with the wild-type allele); lane 5, recombinant $\operatorname{ArcA}$ purified from $E$. coli. (b) $P$. gingivalis UPF carrying a fim $A$ promoter-lac $Z$ fusion and $P$. gingivalis Mflac carrying an $m f a 1$ promoter-lac Z fusion were tested for LacZ activity in the presence or absence of surface extracts $(50 \mu \mathrm{g})$ isolated from the $S$. cristatus strains indicated, or rArCA. The results are means \pm SEM $(n=3)$. Means with different letters are significantly different $(P<0.05$; Bonferroni test $)$; means with the same letter are not significantly different.

deiminase-positive bacteria are found in oral biofilms (Zeng et al., 2006). Arginine deiminase catalyses the hydrolysis of L-arginine to L-citrulline and ammonia, and the latter is believed to be important for oral biofilm $\mathrm{pH}$ homeostasis and caries prevention (Burne \& Marquis, 2000). Besides arginase activity, ArcA can also function as an inhibitor of angiogenesis and tumour growth, which may be due to the depletion of arginine (Gong et al., 2000; Kang et al., 2000; Park et al., 2003). In addition, arginine deiminase plays an important role in the regulation of the level of nitric oxide that is synthesized by NO synthase from arginine, a substrate of arginine deiminase (Gotoh \& Mori, 1999). Since these two enzymes compete for the

same substrate, antiangiogenic activity may result from the suppression of nitric oxide generation. To address whether the inhibitory activity of ArcA depends on enzyme activity, we examined each fraction for its arginase activity. Relatively high arginine hydrolytic activity was detected in the surface extract of $S$. cristatus (Table 2). Arginine hydrolytic activity was abolished in the $\operatorname{arcA}$ mutant, but was partially restored in the surface extracts of the $\operatorname{arcA}$ complemented strain, which is consistent with production of arginine deiminase. Surprisingly, the purified fraction of arginine deiminase (the unbound fraction of the Blue Sepharose column) did not show an increased hydrolytic activity, despite the fact that at least 10 times more inhibitory activity was found in the purified fraction than in the surface extracts (Table 2). We speculated that the arginase activity is not required for intergeneric communication between $S$. cristatus and $P$. gingivalis. To test this hypothesis, communication was tested in the presence of aminoguanidine $(20 \mu \mathrm{M})$ and L-lysine $(5 \mathrm{mM})$, both of which are arginine deiminase inhibitors (Ulisse et al., 2001). These agents completely inhibited the arginase activity in CC5A fractions, but had little effect on the inhibitory activity of the fractions on fimA expression in $P$. gingivalis (Table 2). These data suggest that the catalytic activity of ArcA is not required for the mechanism of inhibition of fimA expression. It appears that ArcA now joins a growing list of bacterial proteins that can have multiple functions, possibly depending on their location (Jeffery, 1999).

\section{DISCUSSION}

P. gingivalis is a secondary colonizer of dental plaque, and is significantly more prevalent in both supra- and subgingival plaque samples from periodontitis subjects in comparison with healthy subjects (Ximenez-Fyvie et al., 2000). The surface attachment of $P$. gingivalis is promoted by adhesive molecules including fimbriae. The long fimbriae, composed of the FimA subunit, mediate adherence of $P$. gingivalis to a variety of oral substrates and molecules, including proline-rich proteins and glycoproteins, statherin, fibrinogen, fibronectin and lactoferrin (Lamont \& Jenkinson, 1998). The fimbriae are also important effector molecules in coaggregation interaction with various early plaque-forming bacteria, such as Actinomyces viscosus (Goulbourne \& Ellen, 1991), Streptococcus gordonii (Lamont et al., 1993) and Streptococcus oralis. Amano et al. (1997) also demonstrated that the FimA Cterminal region is involved in coaggregation with $S$. oralis, with functional domains located in regions spanning amino acids $266-286$ and 287-337. FimA is also a specific adhesin mediating coaggregation of $P$. gingivalis and Treponema denticola, another secondary colonizer (Hashimoto et al., 2003). This specific coaggregation ability with other oral bacteria suggests that the $P$. gingivalis long fimbriae contribute to bacterial integration into dental plaque by interacting with the early and secondary colonizers of 
Table 2. Comparison of arginase activity and the inhibitory activity in protein fractions of $S$. cristatus

\begin{tabular}{|lcc|}
\hline Protein fraction & Arginine deiminase activity $^{\star}$ & LacZ acivity $\dagger$ \\
\hline PBS & $0.04 \pm 0.00$ & $278 \pm 21$ \\
S. cristatus CC5A surface extract $(50 \mu \mathrm{g})$ & $2.12 \pm 0.06$ & $78 \pm 10$ \\
S. cristatus ArcAE surface extract $(50 \mu \mathrm{g})$ & $0.18 \pm 0.01$ & $237 \pm 15$ \\
S. cristatus cArcAE surface extract $(50 \mu \mathrm{g})$ & $1.46 \pm 0.10$ & $152 \pm 18$ \\
CC5A surface extract $(50 \mu \mathrm{g})+10 \mathrm{mM}$ aminoguanidine & $0.32 \pm 0.04$ & $\mathrm{ND}$ \\
CC5A surface extract $(50 \mu \mathrm{g})+5 \mathrm{mM}$ lysine & $0.14 \pm 0.01$ & $\mathrm{ND}$ \\
Purified fraction AS6 $(25 \mu \mathrm{g})$ & $0.8 \pm 0.10$ & $12 \pm 2$ \\
Purified fraction AS6 $(25 \mu \mathrm{g})+10 \mathrm{mM}$ aminoguanidine & $0.15 \pm 0.02$ & $19 \pm 3$ \\
Purified fraction AS6 $(25 \mu \mathrm{g})+5 \mathrm{mM}$ lysine & $0.15 \pm 0.01$ & $21 \pm 4$ \\
\hline
\end{tabular}

${ }^{\star}$ Arginine deiminase levels are means $\pm \mathrm{SD}(n=3)$.

$\dagger$ Expression of the fimA gene was determined by measuring LacZ activity, expressed in Miller units. Results are means $\pm \operatorname{SEM}(n=3)$. ND, Not determined.

dental plaque. Evidently, dental plaque colonization is beneficial to $P$. gingivalis survival in their optimum ecological niche, periodontal pockets. Our earlier finding demonstrated that $S$. cristatus is able to repress expression of the fimA gene in $P$. gingivalis and thus prevent subsequent heterotypic biofilm formation (Xie et al., 2000). The present results provide evidence for the first time that the surface protein arginine deiminase of $S$. cristatus is a signal molecule responsible for cell-cell communication between $S$. cristatus and $P$. gingivalis. As a result of this signal, $P$. gingivalis shuts down expression of the fimA gene. Communication between Gram-positive and Gram-negative bacteria as observed here may be fundamental to bacteria in multispecies biofilms. Interspecies cooperation and competition play important roles in biofilm development and organization. The identification of the molecular basis for an intergeneric contact-dependent communication system provides a molecular basis to begin to understand the differentiation of oral microbial communities from commensal to pathogenic. The study presented here could ultimately lead to the development of novel means to inhibit oral colonization of periodontal pathogens. Oral streptococci are some of the predominant early colonizers of oral plaque (Li et al., 2004), and this unique communication system of sensing foreign species via a surface protein may have been developed to uphold a dominant position in this specialized niche. The consequent inhibition of $P$. gingivalis biofilm formation suggests that susceptibility to periodontal disease may depend to some extent on the microbial composition of the early plaque biofilm and, moreover, that production of arginine deiminase by the oral streptococci may be significant in protection against periodontitis.

\section{ACKNOWLEDGEMENTS}

This work was supported by Public Health Service grants DE014699 (H.X.) and DE12505 (R. J. L.) from the National Institute of Dental and Craniofacial Research.

\section{REFERENCES}

Aas, J. A., Paster, B. J., Stokes, L. N., Olsen, I. \& Dewhirst, F. E. (2005). Defining the normal bacterial flora of the oral cavity. J Clin Microbiol 43, 5721-5732.

Amano, A., Fujiwara, T., Nagata, H., Kuboniwa, M., Sharma, A., Sojar, H. T., Genco, R. J., Hamada, S. \& Shizukuishi, S. (1997). Prophyromonas gingivalis fimbriae mediate coaggregation with Streptococcus oralis through specific domains. J Dent Res 76, 852-857.

Aoki, S. K., Pamma, R., Hernday, A. D., Bickham, J. E., Braaten, B. A. \& Low, D. A. (2005). Contact-dependent inhibition of growth in Escherichia coli. Science 309, 1245-1248.

Aslanidis, C. \& de Jong, P. J. (1990). Ligation-independent cloning of PCR products (LIC-PCR). Nucleic Acids Res 18, 6069-6074.

Burne, R. A. \& Marquis, R. E. (2000). Alkali production by oral bacteria and protection against dental caries. FEMS Microbiol Lett 193, 1-6.

Caldelari, I., Loeliger, B., Langen, H., Glauser, M. P. \& Moreillon, P. (2000). Deregulation of the arginine deiminase (arc) operon in penicillin-tolerant mutants of Streptococcus gordonii. Antimicrob Agents Chemother 44, 2802-2810.

Chung, W. O., Park, Y., Lamont, R. J., McNab, R., Barbieri, B. \& Demuth, D. R. (2001). Signaling system in Porphyromonas gingivalis based on a LuxS protein. J Bacteriol 183, 3903-3909.

Crow, V. L. \& Thomas, T. D. (1982). Arginine metabolism in lactic streptococci. J Bacteriol 150, 1024-1032.

Dong, Y., Chen, Y. Y., Snyder, J. A. \& Burne, R. A. (2002). Isolation and molecular analysis of the gene cluster for the arginine deiminase system from Streptococcus gordonii DL1. Appl Environ Microbiol 68, 5549-5553.

Fletcher, H. M., Schenkein, H. A., Morgan, R. M., Bailey, K. A., Berry, C. R. \& Macrina, F. L. (1995). Virulence of a Porphyromonas gingivalis W83 mutant defective in the prtH gene. Infect Immun 63, 1521-1528.

Gibbons, R. J., Hay, D. I. \& Schlesinger, D. H. (1991). Delineation of a segment of adsorbed salivary acidic proline-rich proteins which promotes adhesion of Streptococcus gordonii to apatitic surfaces. Infect Immun 59, 2948-2954.

Gong, H., Zolzer, F., von Recklinghausen, G., Havers, W. \& Schweigerer, L. (2000). Arginine deiminase inhibits proliferation of human leukemia cells more potently than asparaginase by inducing cell cycle arrest and apoptosis. Leukemia 14, 826-829. 
Gotoh, T. \& Mori, M. (1999). Arginase II downregulates nitric oxide (NO) production and prevents NO-mediated apoptosis in murine macrophage-derived RAW 264.7 cells. J Cell Biol 144, 427-434.

Goulbourne, P. A. \& Ellen, R. P. (1991). Evidence that Porphyromonas (Bacteroides) gingivalis fimbriae function in adhesion to Actinomyces viscosus. J Bacteriol 173, 5266-5274.

Hashimoto, M., Ogawa, S., Asai, Y., Takai, Y. \& Ogawa, T. (2003). Binding of Porphyromonas gingivalis fimbriae to Treponema denticola dentilisin. FEMS Microbiol Lett 226, 267-271.

James, D., Shao, H., Lamont, R. J. \& Demuth, D. R. (2006). The Actinobacillus actinomycetemcomitans ribose binding protein RbsB interacts with cognate and heterologous autoinducer 2 signals. Infect Immun 74, 4021-4029.

Jeffery, C. J. (1999). Moonlighting proteins. Trends Biochem Sci 24, 8-11. Kang, S. W., Kang, H., Park, I. S., Choi, S. H., Shin, K. H., Chun, Y. S., Chun, B. G. \& Min, B. H. (2000). Cytoprotective effect of arginine deiminase on taxol-induced apoptosis in DU145 human prostate cancer cells. Mol Cells 10, 331-337.

Kolenbrander, P. E., Andersen, R. N., Blehert, D. S., Egland, P. G., Foster, J. S. \& Palmer, R. J., Jr (2002). Communication among oral bacteria. Microbiol Mol Biol Rev 66, 486-505.

Kolenbrander, P. E., Palmer, R. J., Rickard, A. H., Jakubovics, N. S., Chalmers, N. I. \& Diaz, P. I. (2006). Bacterial interactions and successions during plaque development. Periodontol 2000 42, 47-79.

Kuramitsu, H. K. \& Wang, B. Y. (2006). Virulence properties of cariogenic bacteria. BMC Oral Health 6 (Suppl. 1), S11.

Lamont, R. J. \& Jenkinson, H. F. (1998). Life below the gum line: pathogenic mechanisms of Porphyromonas gingivalis. Microbiol Mol Biol Rev 62, 1244-1263.

Lamont, R. J., Bevan, C. A., Gil, S., Persson, R. E. \& Rosan, B. (1993). Involvement of Porphyromonas gingivalis fimbriae in adherence to Streptococcus gordonii. Oral Microbiol Immunol 8, 272-276.

Lee, S. W., Hillman, J. D. \& Progulske-Fox, A. (1996). The hemagglutinin genes hagB and hagC of Porphyromonas gingivalis are transcribed in vivo as shown by use of a new expression vector. Infect Immun 64, 4802-4810.

Li, T., Bratt, P., Jonsson, A. P., Ryberg, M., Johansson, I., Griffiths, W. J., Bergman, T. \& Stromberg, N. (2000). Possible release of an ArgGlyArgProGln pentapeptide with innate immunity properties from acidic proline-rich proteins by proteolytic activity in commensal streptococcus and actinomyces species. Infect Immun 68, 5425-5429.

Li, J., Helmerhorst, E. J., Leone, C. W., Troxler, R. F., Yaskell, T., Haffajee, A. D., Socransky, S. S. \& Oppenheim, F. G. (2004). Identification of early microbial colonizers in human dental biofilm. J Appl Microbiol 97, 1311-1318.

McNab, R., Ford, S. K., El-Sabaeny, A., Barbieri, B., Cook, G. S. \& Lamont, R. J. (2003). LuxS-based signaling in Streptococcus gordonii: autoinducer 2 controls carbohydrate metabolism and biofilm formation with Porphyromonas gingivalis. J Bacteriol 185, 274-284.

Merritt, J., Kreth, J., Shi, W. \& Qi, F. (2005). LuxS controls bacteriocin production in Streptococcus mutans through a novel regulatory component. Mol Microbiol 57, 960-969.
Nelson, D., Goldstein, J. M., Boatright, K., Harty, D. W., Cook, S. L., Hickman, P. J., Potempa, J., Travis, J. \& Mayo, J. A. (2001). pHregulated secretion of a glyceraldehyde-3-phosphate dehydrogenase from Streptococcus gordonii FSS2: purification, characterization, and cloning of the gene encoding this enzyme. J Dent Res 80, 371-377.

Park, I. S., Kang, S. W., Shin, Y. J., Chae, K. Y., Park, M. O., Kim, M. Y., Wheatley, D. N. \& Min, B. H. (2003). Arginine deiminase: a potential inhibitor of angiogenesis and tumour growth. $\mathrm{Br} J$ Cancer 89, 907-914.

Rickard, A. H., Palmer, R. J., Jr, Blehert, D. S., Campagna, S. R., Semmelhack, M. F., Egland, P. G., Bassler, B. L. \& Kolenbrander, P. E. (2006). Autoinducer 2: a concentration-dependent signal for mutualistic bacterial biofilm growth. Mol Microbiol 60, 1446-1456.

Scannapieco, F. A., Torres, G. I. \& Levine, M. J. (1995). Salivary amylase promotes adhesion of oral streptococci to hydroxyapatite. J Dent Res 74, 1360-1366.

Tao, L., LeBlanc, D. J. \& Ferretti, J. J. (1992). Novel streptococcalintegration shuttle vectors for gene cloning and inactivation. Gene 120, 105-110.

Thirkill, C. E., Song, D. Y. \& Gregerson, D. S. (1983). Application of monoclonal antibodies to detect intraocular mycoplasma antigens in Mycoplasma arthritidis-infected Sprague-Dawley rats. Infect Immun 40, 389-397.

Tobian, J. A., Cline, M. L. \& Macrina, F. L. (1984). Characterization and expression of a cloned tetracycline resistance determinant from the chromosome of Streptococcus mutans. J Bacteriol 160, 556-563.

Ulisse, S., Gionchetti, P., D’Alo, S., Russo, F. P., Pesce, I., Ricci, G., Rizzello, F., Helwig, U., Cifone, M. G. \& other authors (2001). Expression of cytokines, inducible nitric oxide synthase, and matrix metalloproteinases in pouchitis: effects of probiotic treatment. Am J Gastroenterol 96, 2691-2699.

Wang, B. Y. \& Kuramitsu, H. K. (2005). Interactions between oral bacteria: inhibition of Streptococcus mutans bacteriocin production by Streptococcus gordonii. Appl Environ Microbiol 71, 354-362.

Xie, H., Cai, S. \& Lamont, R. J. (1997). Environmental regulation of fimbrial gene expression in Porphyromonas gingivalis. Infect Immun 65, 2265-2271.

Xie, H., Cook, G. S., Costerton, J. W., Bruce, G., Rose, T. M. \& Lamont, R. J. (2000). Intergeneric communication in dental plaque biofilms. J Bacteriol 182, 7067-7069.

Xie, H., Kozlova, N. \& Lamont, R. J. (2004). Porphyromonas gingivalis genes involved in fimA regulation. Infect Immun 72, 651-658.

Ximenez-Fyvie, L. A., Haffajee, A. D. \& Socransky, S. S. (2000). Microbial composition of supra- and subgingival plaque in subjects with adult periodontitis. J Clin Periodontol 27, 722-732.

Zeng, L., Dong, Y. \& Burne, R. A. (2006). Characterization of cisacting sites controlling arginine deiminase gene expression in Streptococcus gordonii. J Bacteriol 188, 941-949.

Edited by: M. A. Curtis 